DOE/NASA/1044-12

NASA TM-81642

\title{
Design Studies of Continuously Variable Transmissions for Electric Vehicles
}

(NASA-TM-81642) DESIGN STODIES OF

CONTINDOUSLY VABIABLE TRANSMISSIONS FOB

ELECTRIC VEHICLES (NASA) 18 P HC AO2/4F AOI

CSCL $13 I$

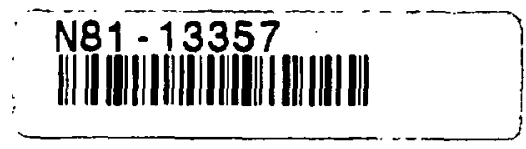

$0.3 / 37 \quad 29440$

Richard J. Parker, Stuart H. Loewenthal, and George K. Fischer

National Aeronautics and Space Administration Lewis Research Center

Work performed for

U.S. DEPARTMENT OF ENERGY

Conservation and Solar Energy Office of Transportation Programs

Prepared for

Society of Automotive Engineers Congress

Detroit, Michigan, February 23-27, 1981 


\section{NOTICE}

This report was prepared 10 document work sponsored by the United Slates Government Netther the United States nor ils agent, the United Slates Depanment of Energy. nor any Federal employees. nor any ol their contractors. subcontractors or theit employees, makes any warranty. express or implied. or assumes any legal liability or responsibility for the accuracy, completeness, or usefulness of any information. apparatus. producl or process disclosed. or represents that its use would not intringe privalely owned rights

\footnotetext{
A.
} 


\section{GENERAL DISCLAIMER}

This document may be affected by one or more of the following statements

- This document has been reproduced from the best copy furnished by the sponsoring agency. It is being released in the interest of making available as much information as possible.

- This document may contain data which exceeds the sheet parameters. It was furnished in this condition by the sponsoring agency and is the best copy available.

- This document may contain tone-on-tone or color graphs, charts and/or pictures which have been reproduced in black and white.

- This document is paginated as submitted by the original source.

- Portions of this document are not fully legible due to the historical nature of some of the material. However, it is the best reproduction available from the original submission. 


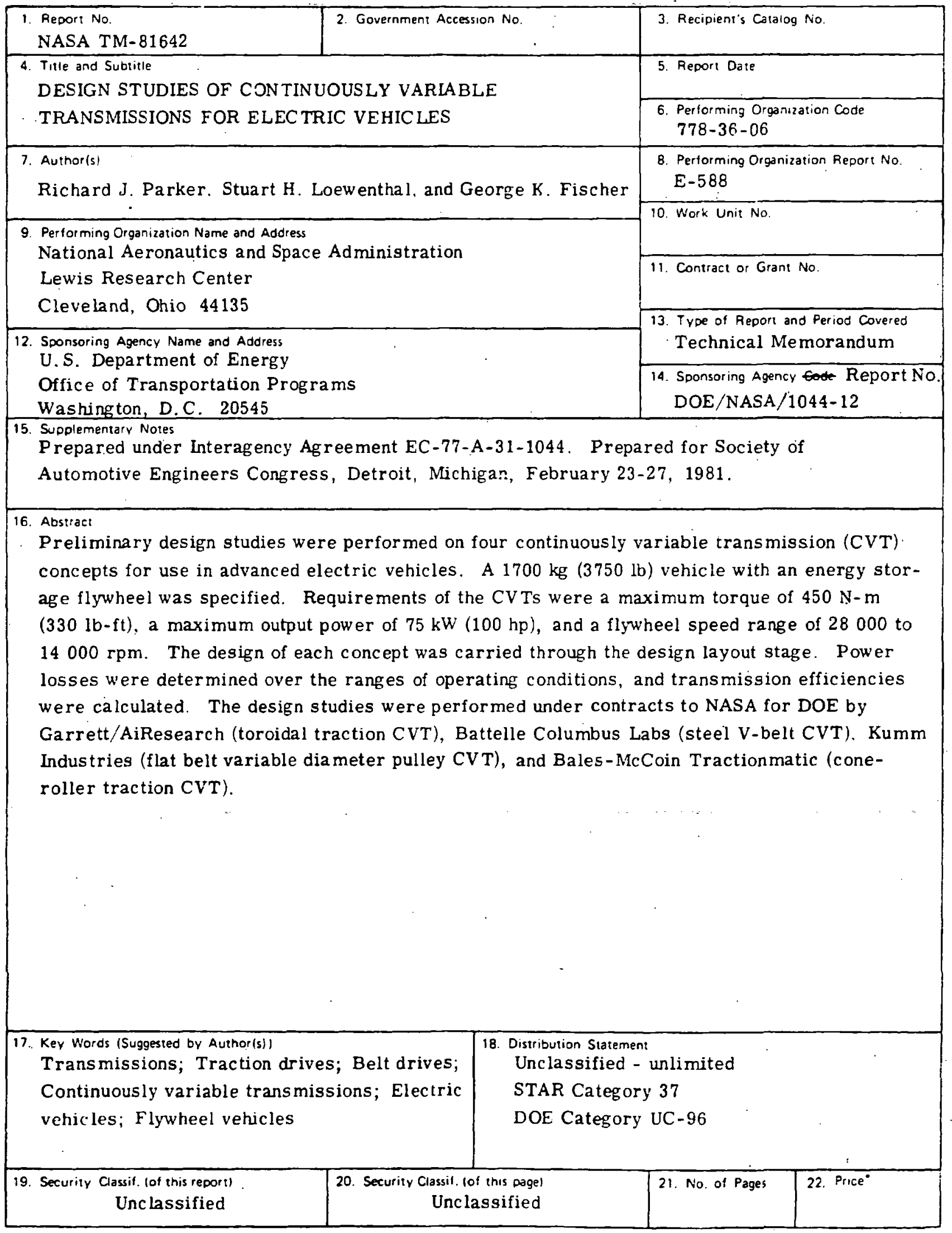

- For sale by the Nalional Technical Intormation Scivice. Springlir-lif. V/1p.ma 22161 
DOE/NASA $/ 1044-12$

NASA TM-81642

\section{Design Studies of Continuously Variable Transmissions for Electric Vehicles}

Richard J. Parker, Stuart H. Loewenthal, and George K. Fischer

National Aeronautics and Space Administration

Lewis Research Center

Cleveland, Ohio 44135

Performed for

U.S. DEPARTMENT OF ENERGY

Conservation and Solar Energy

Office of Transportation Programs

Washington, D.C. 20545

Under Interagency Agreement EC-77-A-31-1044

Society of Automotive Engineers Congress

Detroit, Michigan, February 23-27, 1981 


\section{ABSTRACT}

Preliminary design studies were performed on four continuously variable transmission (CVT) concepts for use in acivanced electric vehicles. A $1700 \mathrm{~kg}(3750 \mathrm{lb})$ vehicle.with an energy storage flywheel was specified. Requirements of the CVTs were a maximum torque of $450 \mathrm{~N}-\mathrm{m}$ ( 330 $1 \mathrm{~b}-\mathrm{ft})$, a maximum output power of $75 \mathrm{kH}(100 \mathrm{hp})$, and a flywhee 1 speed range of 28000 to 14000 rpm. The design of each concept was carried through the design layout stage. Power losses were determined over the ranges of operating conditions, and transmission efficiencies were calculated. The design studies were performed under contracts to NASA for DOE by Garzetr/AiResearch (toroidal traction CVT), Battelle Columbus Labs (steel V-belt $(V T)$ ), Kumm Industries ( $f$ lat belt variable diameter pulley CVT), and Bales-McCoin Tractionmatic (cone-roller traction CVT).

FLYWHEEL ENERGY STORAGE can improve the performance of electric and hybrid vehicles ( 1 to 4 ).* Also, the flywheel offers short-term energy storage and leveling of current draw on the batteries. With a flywheel, electric vehicle performance can be maintained over the life of the battery regardless of age or depth of discharge of the battery (5). Actual performance tests show that regenerative braking $c a n$ increase the range of electric vehicles (6). A flywheel can be used for regenerative braking by transferring kinetic energy from the vehicle to the flywheel.

Studies have recent ly been completed on the conceptual design of several advanced electric vehicle propulsion systems ( 7 and 8 ). Three of the four systems studied include flywheels. The flywheels are either mechanically or electrically coupled to the drive train. For flywheels mechanically coupled, a continuously variable transmission (CVT) is required to provide matching of the independent flywheel and vehicle speeds. CVTs a re also being considered for electric vehicle systems without flywheels and have shown some advantages, such as reducing the required battery weight ( 8 ).

At present, CVTs have not been sufficiently developed for immediate application to electric

*Numbers in parentheses designace References at end of paper. vehicles. A significant factor in this application is the broad ratio range required of the CVI for a system with a flywheel, since the flywheel speed may be at its maximum value when the vehicle speed is lowest: Other concerns raised in the propulsion system design studies of $(\cdot 7$ and $B$ ) are life, weight, and cost of CVTs suitable for electric venicles.

To initiate a development program for CVTs, preliminary design studies were performed on four CVT concepts which include traction and variable belt types. These studies were performed as a part of the DOE Electric and Hybrid Vehicle Program under contract to NASA Lewis Research Center by the contractors listed in table I. Each study was for the preliminary design of a specific CVT for a 1700-kg (3750-1b) vehicle containing a $1.8-\mathrm{MJ}(0.5 \mathrm{kWh})$ energy storage flywheel. Requirements of the CVTs were a flywhel speed range of 28000 to $14000 \mathrm{rpm}$, a maximum output torque of $450 \mathrm{~N}-\mathrm{m}(330 \mathrm{lb}-\mathrm{ft})$, a maximum output power of $75 \mathrm{~kW}(100 \mathrm{hp})$, and an output speed range of zero to $5000 \mathrm{rpm}$. Following the se preliminary design studies, two or more of the CVT concepts are to be selected for detailed design, fabrication, and testing with a goal of making an advanced CVT available for use in electric vehicles by the year 1985 .

The objective of each of the design studies was to determine the best arrangement of a specific CVI concept, select and size the components for a 90-percent survival life of 2600 hours, and determine power losses and efficiencies over the range of operating conditions. A preliminary design layout of each CVT was completed. The results of these design studies were published in references ( 9 to 12). In this paper, the results of the studies are summarized, and the CVTs are compared based on such criteria as efficiency, size, weight, cost, and the extent of new technology advancements required to make each CVT suitable for electric vehicles.

\section{DESIGN REQUIREMENTS AND CRITERIA}

The preliminary design of each CVT concept was performed within certain design requirements and criteria specified in each contract statement of work. These design requirements were not selected for any specific vehicle but as a common basis for comparisons among the various CVT concepts. The CVT was to be arranged in the vehicle. drive train shown in figure 1. A 1700-kg (37501b) vehicle was specified which included a 1.8-MJ $(0.5-\mathrm{kWh})$ maximum usable energy flywheel. Selec- 
tion and sizing of components was based on the following factors:

1. The speed ratio of the CVT was to be continuously controllable over the range of input speeds (flywheel output) of 28000 to $14000 \mathrm{rpm}$ and output speed (differential input) of zero to $5000 \mathrm{cpm}$. The option was available to select a continuously controllable minimum CVT output speed of $850 \mathrm{rpm}$ and use a silpping clutch element to regulate differential input speed to zero. Using the $850 \mathrm{cpm}$ minimum speed, the ratio range requited of the CVT is 11.76 to 1 .

2. The maximum transient power output was 75 kW ( $100 \mathrm{hp})$.

3. The maximum transient torque output at wheel slip was $450 \mathrm{~N}-\mathrm{m}(330 \mathrm{lb}-\mathrm{ft})$.

4. The maximum time from maximum to minimum reduction ratio, or vice versa, was to be $2 \mathrm{sec}^{-}$ onds or less.

5. The life of the CVT was to be 2600 hours at a 90-percent probability of survival (10-percent life). This life was to be estimated at a weighted average output power of $16 \mathrm{kh}(22 \mathrm{hp})$, an output speed of $3000 \mathrm{rpm}$, and an input speed of 21000 rptri.

6. The CVT was not required to provide reverse rotation for reverse vehicle motion, since reverse could be accomplished by reversing electric'motor rocation.

7. The CVT was to be capable of bi-directional power flow for regenerative braking and charging of the flywheel.

8. The CVT was to be capable of withstanding all sudden shock loads and sudden torque conditions that would reasonably be expected in typical aucomotive applications.

9. The CVT was to include a means to disengage the flywheel from the drive train for parking and reverse.

The CVT and associated drive system components were to be designed on the basis of the following criteria in order of overall importance:

1. High efficiency - The CVT was to have high efficiency over its entire operating speccrum. Special atcention was to be given to maximizing efficiency at those operating conditions in which it spends most of its operating time, that is, the specific weighted average power and speeds given above.

2. Low cost - Future production costs of the CVT on a basis of 100000 units per year was to be an early consideration. The use of special manufacturing processes and materials was to be avoided. Design techniques and drive system components such as bearings, gears, and seals were to be typical of and consistent with automotive practice.

3. Size and weight - The overall size and weight of the CVT, including suitable controls and all ancillary mechanical components, were to be not significant ly greater than present automotive transmissions of equal horsepower capability.

4. High reliability - The CVT was to be designed to operate a minimum of 2600 . hours with a 90 -percent reliability at the weighted average powet and speed conditions given above.

5. Noise - Potential noise generating sources were to be eliminated or noise that was unavoidably generated was to be contained within the housing.

6. Controls - The control system used to operate the CVI was to be stable and reliable, was to provide driver "feel" and response similar to that of a current automatic transmission equipped, internal combustion engine passenger vehicle. The control sytstem was to be an integral part of the CVT design.

7. Maintainability - The CVT was to be designed with maintainability equal to or better than that of current automatic transmissions. All internal components which require normal maintenance or occasional replacement were to be made readily accessible.

\section{DISCUSSION OF CVT CONCEPTS}

The four CVT concepts for which design studies were performed for the electric vehicle with flywheel application are listed in table I. In this section, the basic concept and the arrangement of each CVT will be discussed.

STEEL V-BELT CVT - The steel V-belt CVT ar rangement is shown schematically in figure 2 . Two steel, variable ratio $V$-belt and pulleys in series are used to cover the 11.76 ratio range required. A modulating clutch is used co vary output speed from $850 \mathrm{rpm}$ to zero, to disconnect the flywheel/transmission from the rest of the drive train, and to protect the CVT from sudden torque transients. A 2.8 to 1 spur gear set reduces the flywheel speed to that of the highspeed belt.

The pair of $V$-belt $d r i v e s$ act as reducers only, as power flaws from the flywheel. The maximum reduction ratio range of the high-speed belt is from $1: 1$ to $3.94: 1$. For the low-speed belt, the range is from $1: 1$ to $3.31: 1$. The high-speed belt carries less torque and its cross section is somewhat smaller than the low-speed belt.

Figure 3 is a preliminary layout of the steel V-belt CVT. The CVT is controlled by an electro-hydraulic control system. The axial clamping force of the pulley is provided by hydraulic pressure applied in a chamber behind one face of each pulley set. This force is required to prevent belt slippage and accomplish ratio changes. Individually controlled hydraulic pressures are applied to each of four pulleys and also to the hydraulically actuated modulating clutch. The hydraulic pressure required at each location is computed by a vehicle microprocessor and is based on the anount and direction of torque desired and on the instantaneous ratios. The axial force imposed on the pulleys is regulated to provide the best compromise between drive performance and belt life.

Shifting is accomplished by increasing or decreasing the axial force on the appropriate pulleys. During shifting, one pulley sheave slides on the shaft. The other sheave is fixed to the shaft. The shaft is free to move axially, but is constrained by an axially grounded synchronizing link in such a way as to keep the belt centerline in a fixed position. This action avoids the belt misalignment chat occurs with the usual simple means of shifting whe only one 
sheave is moved. The hydraulic control fluids are communicated to the control cylinders through face seals at the pulley support stiaft ends and then through the shaft. More details of the steel $V$-belt CVT are given in reference (9).

Steel V-Belt Features - The steel compression V-belt proposed for use in this CVT has had some prior hardware development by the authors of reference (9). The steel belt is similar in construction to the belt used by van Doorne in Holland in their industrial variable speed drives and in prototype automobile transmissions (13).

The steel V-belt proposed consists of a series of solid cross struts, strung along a single set of nested flexible bands in such a manner. as to allow them to slide freely along the bands. The belt is illustrated in figure 4 . The ends of the struts contact the face of the V-shaped pulleys. The strut sides contact each other and transmit compressive forces from strut to strut along the length of the belt. It is by means of chese "pushing" forces that powe' is transmitted from pulley to pulley. The driver pulley pushes the driven pulley through the stack of struts. The belt is thus temed a compression belt. The bands which contain the individual seruts carry a tensile force which is essentially unvarying throughout the length of the belt. This tensile force is somewhat greater than the maximum com pressible force being transmitted. The bands force the struts into the grooves of the pulley and keep the belt from Duckiling. Details of the proposed strut design, band material, and component stresses are given in reference (9).

Control system. - The proposed electrohydraulic control system, using an overall vehicle control microprocessor, incorporates closedloop torque feedback. The control system output signals operate the hydraulic valves which apply hydraulic pressure to the appropriate pulley and the modulating clutch.

FLAT BELT CVT - The arrangement of the $f l a t$ belt CVT is shown schematically in figure 5. A flat rubber belt and a pair of pulleys which can be made to change diameter are used in combination with a differential gearing arrangement. The CVT uses a conventional automotive type synchronizer to shift Erom a low-speed (power recirculating) mode to a high-speed (direct drive) mode of operation, thus using the ratio range of the variable pulieys twice to cover the required speed range down to zero output speed.

The power flow passes through both the belt and the planetary differential gear in the low speed mode, and through the belt only in the high-speed mode. The direction of power flow through the belt in the high-speed mode is reversed from the power flow in the low-speed mode, that is, driver and driven pulley functions are reversed.

The flat belt CVT arrangement in figure 5 is slight ly different than that shown in figure 1 . In the flat belt CVT, the electric motor is shown at the input of the CVT, rather than between $t$ he CVT and the wheels. This option would allow the use of a higher speed dc motor with projected advantages of improved efficiency, smaller size, and $l i g h t e r$ weight. It does not significantly alter the requited operating ranges or conditions imposed on the CVT. An electric clutch is located between, the flywheel input and the motor input to disengage the flywheel for reverse opera$t$ ion by the motor. Gearing reduces the speed at which the variable pulleys operate to a maxinum of approximately $10000 \mathrm{rpm}$. The cotal ratio range of the variable pulleys is $4: 1$.

Figure 6 is a preliminary layout of the flat belt CVT. More details are given in reference (12).

Flat Belt, Variable Pulley Features - The unique components in the flat belc CVT are the variable diameter pulleys shown in figure 7 . Variable diameter operation is accomplished by a series of drive elements which are located between pairs of inner and outer discs and positioned radially by oppositely angled, curved guideways. As the inner and outer discs are rotated through a small are relative to one another, the elements are moved radially to a larger or smaller racius as desired. The use of radially movable elenents such as these with a flat rubber belt is described in a U.S. patent by Kumm (14).

The inner and oucer discs of each pulley are positioned and moved by a hydraulic accuator which rotates with the pulley (fig. 8). The inner discs are connected to one side of pressurized triangular volume sectors (case) in the rotary actuator and the outer discs are connecteo to the other side (shaft) of the sectors. The fluid pressure difference between the sectors causes the inner and outer discs to rotate in opposite ditections through a small arc. The torque developed by the rotary actuator, results in moving the drive elements toward a different radius on each pulley to tension the belt to prevent slippage.

Applying a large pressure differential between the actuators of the two pulleys will cause the drive elements to be positioned at a larger radius on one pulley and at a smaller radius on the other pulley, due to the resulting tensions and fixed belt length. Thus, by controlling the pressures to the actuators, the speed ratio of the transmission may be varied over the limit of the pulley geometry while transmitting power at various speeds. Appropriate seals are used to keep the hydraulic actuating and lubricating fluid out of the flat belt cavity.

Control System - A single lever control is used by the operator to select the vehicle speed. This lever moves a spool in the speed servo valve to obtain either an increase or decrease in transmission torque output. The hydraulic system then controls the pressure to the rocary actuators. A corque sensor is used in combination with the hydraulic rotary actuators to vary the cension on the flat belt as needed to prevent belt slippage without overloading. Another portion of the hydraulic circuit is used to control the speed ratio across the pulleys, according to the position of an operator actuated single lever.

The shift irom the low-speed to the highspeed mode and vice versa, occurs when the drive elements of pulley A (see fig. 5) have reached the ir maximum radius, at which time the low-speed and high-speed gears in the synchronizer are at 
the same speed. At that time, an electrical solenoid automatically operates the syrichronizer. TOROIDAL TRACTION CVT - The preliminary design layout of the coroidal traction CVT is shown in figure' 9. It is a dual-toroidal cavity drive with two rollers per cavity with power recirculating gearing. It is infinitely variable so that the output shaft may be brought to zero speed witnout a clutch. The design incorporates three gear sets within the CVT housing.

The input shaft is connected to the flywheel through a $3: 1$ planetary reduction gearset. The carrier of this gearset can be released with a clutch mechanism to decouple the CVT from the flywheel. The ring gear of the reduction gearset connects cirectly to the mainshaft of the CVT. On the mainshaft are the input (outer) toroidal discs and the sun gear of the planetary differential output gearset. The output (inner) toroidal discs are geared to the ring gear of the output planetary differential gearset through the transfer shaft. The planet carrier of this gearset is connected to the output shaft.

Power flow through the CVT is in through the input reduction gearset, across the coroidal cavities, through the transfer shaft, and out through the output planetary gearset. Part of the power flows to the output shaft; the remaining power returns through the sun gear of the output gearset to the input toroidal discs. Thus the power recirculating between the toroical cavities and the output gearset is always somewhat greater than the output power. The output shaft rotates in the same direction as the ring gear. Minimum output speed occurs when the toroidal drive is in reduction. The cotal ratio range across the toroidal cavity is approximately 5.8:1. A torque 1 imiting device is included in the transfer shaft to slip at a predetemined torque level, limiting overloads on the drive. Toroidal traction drives for automobile applications are not new, having seen early use over 50 years ago. Current ly, in Europe a similar dual-cavity toroidal traction drive is being developed (15) zor spark ignition engine application.

Toroidal Cavity Features - The proposed coroidal traction drive is a full-toroid or oncenter configuration. This means that the center of the load rollers is at the center of the toroidal cavity.

The two input discs of the dual-cavity toroidal drive are attached to the main shaft. The output discs are connected to each other by a sleeve; one cisc firmly attached and the other splined to the sleeve to allow axial movement. A load cam mechanism, located between the ourput discs, controls the normal force between the discs and the drive rollers as a function of the torque on the output discs. The load cam is pinned to the output gear which meshes with a gear on the transfer shat. As the output toroidal discs are driven, the cam rollers roll against the output disc and load cam, generacing an axial force on the output discs. This force increases directly wich torque on the output discs. Its magnituce is controlled by the shape of the load cam.

The axial force loads the output discs against the input discs through the orive to 11ers. It is reacted by the mainshaft, and is isolated from the housing. The romal force on the traction contact is dependent on the axial force and the orientation of the drive rollers in the toroidal cavity. The load cam mechanism assures that there is always sufficient contact load to transmit the required traction force without slip while minimizing the amount of overloading.

The drive rollers are positioned between the input and output discs by trunnions as shown in figure 10. The trunnions allow the axis of the rollers to rotate in the toroidal cavity. A hydraulic force balance roller control system is employed to position the roller. The roller position sets the ratio across the toroidal cavity, thereby controlling output speed.

Cortrol System - The CVT ratio is controlled. by applying a transverse force to the drive rollers so that the rollers steer to the rolling paths on the discs that produce the commanded tilt or ratio change. This is a force-feedback actuation system that is hydraulically operated with pressure-balanced hydraulic load control cylinders as shown in $\mathrm{f}$ igure 10.

Transverse movement of the drive rollers in the toroidal cavity changes the tangential forces on the drive roller. Steering action occurs when the sum of the tangential forces on a roller are different from the force from the hydraulic cylinder. The roller seeks the position where the Forces are balanced. Each roller is controlled independently by its own hydraulic cylinder. With all cylinders connected in paralle1, all the rollers must find a roll path where they will have equal tangential forces and thus equal. loads. By controlling the hydraulic pressure in the cylinders, the tangential forces on the rollers, and hence the torque produced by the transmission, is controlled. More detail of the control system and its operation is given in reference (11).

CONE ROLLER TRACTION CVT - The preliminary design of the cone-roller traction CVT is shown in figure 11 . The variable ratio portion of the CVI consists of a traction roller which can be moved axially along and in contact with four inclined cones, thus varying the rolling radius of the cones. The CVT includes a recirculating pow er differential gear set at the output to accomplish the required ratio range. An input planetary gear set reduces the flywheel speed by a factor of approximately 3 . A band clutch is used on the input ring gear to decouple the flywheel for reverse vehicle operation and parking.

Power flow is from the cartier of the input reduction gear set to a splined through-shaft which carries the axially-movable traction rol1er. The traction rolles drives the cones which in turn drive the ring gear of the output planetary through a set of bevel-nelical idler gears. The carrier of the output planetary is the output of the CVT. The sun gear of the output planetary, attached to the through-shaft, recirculates power back to the traction assemily. This provides the differential action which allows the output speed range of 850 to 5000 Ipm to be accomplished. For lower output speeds, the flywheel is decoupled by the clutch on the input 
planetary. The ratio range across the cone/ rollez traction drive is from $1.7: 1$ to $6.2: 1$ overdrive for a tocal of approximately 3.6 overall.

Variable-Ratio Assembly - The traction roller is positioned along the through-shaft on a ball spline by a wom-screw drive as shown in figure 11. The nomal load in the traction contacts is supplied by a hydraulic piston which contains a ball bearing supporting the small end of each cone. The magnitude of the normal load is controlled by modulating the pressure in the hydraulic cylinder. The control system varies this pressure according to output torque requirements.

Control System - The traction contact control system utilizes a microprocessor to make maximum use of the torque capacity of a traction contact. The instantaneous torque capacity of a traction contact depends on the nomal load between the roller and cones and the available traction coefficient of the lubricant under the given operating conditions. The relation between traction force (or torque capacity) and slip in the contact for a given nomal load, lubricant, and operating condition is shown in figure 12 . peak is present which is the maximum traction force that $c$ an be transmitted before impending slip. The slip value occurring at the peak can be thought of as the optimum slip value for a given normal load. The peak is higher for higher nomal loads. The control system is designed to keep the conditions in the traction contact at or near this peak since the normal load would be at its lowest value to transmit the required torque.

Encoders and toothed discs attached to the cones and the rollers monitor their rotational speeds. A linear transducer monitors the axial position of the traction roller. Instantaneous slip conditions are determined by comparing the measured speed ratio and the reference geometric ratio (from roller axial position). The microprocessor analyses the information based on the rate of change of slip with normal load and sends an output signal to the pressure modulating valve in the cone loading hydraulic system. System pressure is increased when the slip is too high, so that a greater normal ioad is imposed with will reduce the slip to the required value. Conversely, pressure is decreased if slip is too low, to increase slip to the required value. By controlling loads in this manner, efficiency and life of the CVT can be improved. Furcher details of the cone-roller traction CVI and control system are given in reference (i0).

PREDICTED PERFORMANCE - The preliminary design of eaci CVT was evaluated for power loss, efficiercy, weight, and size. To estimate the efficiency, the iosses.in the bearings, gears, and seals were combined with hydraulic system losses and traction contact losses o: belt contact losses, as applicable, to give overall CVT losses. The losses were calculated over the operacing range of the CVT.

The caiculated efficiencies for each CVI are shown in figure 13 for an output power of ib $\mathrm{kW}$ ( $22 \mathrm{hp}$ ) and an output speed of $3000 \mathrm{rpm}$ over the range of flywheel speeds. This condition is a weighted ave rage power condition used to design and compare the various CVTs on the basis of life and efficiency. A very small effect of input (flywheel speed) is shown. The steel V-belt and flat beit CVTs show predicted efficiencies somewhat greater than the toroidal traction and cone-rolle: tracton. CVIs but all are in excess of 90 percent.

In table II, efficiencies at several typical vehicle operating concitions are shown. Again, the steel V-belt and flat belt CVIs tend to have a slight advantage at nearly all conditions, but ali efficiencies are high, in the range of $86: 5$ to 97 percent.

One of the criceria for the preliminary design was that the size and weight should not be significantly. greater than present automotive transmissions of equal power rating. No restriction on shape or input/output relative position (such as inline or offset) were given. As seen by the layouts in figures $3,6,9$, and 11 , the shapes vary considerably. Table III gives dimensions of the four CVT designs. The two traction CVTs have ialine input and output shafts, whereas both belt-type CVTs have of fsets.

The estimated weights of the four CVI designs are also given in table III. All are equal or less than the weight of comparable automatic transmissions which generally are in the range of from 68 to $82 \mathrm{~kg}$ ( 150 to 180 lb).

Cost estimates based on high volume manufacture of 100000 units per year were difficult to make because detailed drawings were not prepared in the preliminary design. However, there are many similarities between the parts of these CVTs and present automatic transmissions. Machining and processing techniques for the unique CVT components are or will be well established by the time production commences. It is, therefore, expected that costs per pound for the CVIs would be similar to that of present automatic transmissions.

TELHNOLOGY ADVANCEMENTS REQUIRED - Before these CVI concepts will be viable for large-scale electric vehicle application, extensive testing and development will be required. The four CVT concepts have received different levels of previous development. None of them are presently in production for automotive use. The basic concepts of steel $V$-belts, toroidal traction drives, and cone-roller traction drives have each been fabricated and tested and have had some procotype testing in internal-combustion engine automobiles. The flat belc CVr, on the other hand, has not yet been fabricated or tested.

To satisfy the design requirements and criteria of this program, each of the CVT concepts require unique components and advancements in technology as identified by the contractors in references ( 9 to 12 ).

For the steel V-belc C.VT, the selection of band material and determination of its fatigue strength is of prime importance. Cost effective means of fabricating tine band and the struts of the steel $V$-belt will need to be developed. The electronydraulic controi valves required for pulley actuation will require some development to be cost effective in an automotive system.

The flat belt CVT has been designed to use existing flat belt tectrnology. It is possibie 
that imfroved flat belt construction, perhaps as described in reference (12), could give improved belt life or allow greater bending stresses to be used in the belt. The variable pulley concept, not having been fabricated or testec, will require some development to perfect its operation. In addition, the fabrication of strong, 1 ightweight drive elements must be made cost effeccive, possibly by using extrusion or casting processes.

For the traction type CVTs, special lubricants must be used that exhibit a high coefficient of traction, that.is, the ratio of the transmitted tangential force to the nomal force in the contact. These traction fluids, as they are called, allow the use of lower contact loads and, thus, give longer rolling-element fatigue life to the traction contacts and higher power density than conventional lubricants.

Some development of traction fluids is needed. The change in viscosity with temperature Eor typical traction fluids is greater than acceptable for automotive use. Thereiore, the viscosity index must be improved. Air entrainnent in traction fluids has been observed in some cases to be greater than acceptable and needs to be minimized.

in addition, more test data is needed on the traction properties of these traction fluids under conditions sinulating those in actual transmissions. The limits on the amount of contact power loss that $c$ an be tolerated before surface damage occurs in the traction contacts also needs to be determined.

All four of the CVT concepts require control systems that re spond rapidly to driver commands and control the magnitude and direction of power flow through the CVT. This requirement is cifficult since the CVT is located between the flywheel and the vehicle, both of which have high inertia.

It is desired that the control system provide a driver feel similar to that of current automobiles with automatic transmissions.

Whether similar driver "feel" could be achieved with a flywheel-electric vehicle or whether drivers would accept a different driveability characteristic are questions which as of now are unanswered. In tomorrow's automobile, the transmission control system would necessarily be integrated with the vehicle control system which will, in all liklihood, use a microprocessor. Control systems using microprocessors should provide smooth, reliable operation of a CVI equipped, flywheel-electric vehicie.

PERFORMANCE TESTING - As a follow-on effort to the preliminary design stucies, it is planned that at least two of the concepts will be selected for detailed design, Fabrication, and performance testing. Criteria for selection of those concepts for further work include the perFormance predicted in the preliminary study, the confidence that the concept can fulfill the design requirements and criteria specified, the degree of risk anticipated with the development, and the amount of previous anc current development on similar concepts.

The follow-on efforts are expected to be performed in two phases. Initially, the critical variable-ratio elenents of each CVI will be fabricated and tested. In a second phase, pending encouraging results from the initial phase, the entire CVT would be fabricated and tested. This program is expected to be a 3 to 4 year effort, and should make one or more of the CVTs available for prototype electric vehicle testing by 1985 .

The technology developed in this program is expected to be suitable for use in alternate vehicles such as hybrid electric vehicles, electric vehicles without a flywheel, or heat engine vehicles. These alternate vehicles would require different power ratings and speed ratio ranges from those designed for the flywheel/electric vehicle, but the variable-ratio element and its technology would be directly applicable.

\section{SUMMARY}

In summary, preliminary design studies were performed on four CVT concepts for use with a flywhel equipped electric vehicle of $1700 \mathrm{~kg}$ gross weight. The flywheel speed range was from 28000 to $14000 \mathrm{rpm}$, delivering a maximum of 75 $\mathrm{kW}$ through the CVT whose output speeds ranged from zero to $5000 \mathrm{rpm}$. System life was to exceed 2600 hours at a 90-percent projability of survival. Efficiency, size, weight, cost, reliability, maintainability, and controis were evaluated for each of the four concepts. The CVT concepts studied consisted of a steel V-belt cype (Battelle), a flat rubber belt type (Kumm), a toroidai traction type (AiResearch), and a cone/ roller traction type (Baies-McCoin).

All CVTs exhibited relatively high calculated ef Eiciencies ( 86 to 97 percent) over a broad range of vehicle operating concitions. Estimated weight and size of these transmissions were comparable to or less than an equivalent automatic. transmission. The preiminary designs generated uncer this study were sufficiertly promising to plan detailed design, fabrication, and performance testing phase with at least two of the concepts.

\section{REFERE NCES}

1. McAlevy, R. F. III, "The Impact of $\dot{F} 1 y-$ wheel-Transmissions on Automobile Performance: A Logical Basis for Evaluation," UCRL-52758, April 1979.

2. Schwartz, M. W., "Assessment of the APplicability of Mechanical Energy Storage Devices to Electric and Hybrid Vehicles": Volume 1 Executive Summary UCRL -52773 , Vo1. 1, May 1979 and Volume 2, UCRL-S2773, Vol. 2, May 1979.

3. Economic and Technical Feasibility Study for Energy Storage Flywheels," HCP/M1066-01. (Previously issued as ERDA 76-65), May 1978.

4. Burrows, C. R., Price, G., and Perry, F. G., "An Assessment of' Flywhel Energy Storage in Electric Vehicles," SAE paper 800885 .

5. Kirk, Robert S. and Davis, Philip W., "A View of the Future Pocential of Electric and Hybrid Vehicies," Electric and Hybrid Vehicle Program Quarterly Report, DOE/CS-0026-10; May 1980. 6. "State-of-the-Azt Assessment of Electric and Hybrid Vehicies," NASA TM-73756, Sept. 1977. 
7. Younger, Francis $C$. and Lackner, Heinz, "Study of Advanced Electric Propulsion System. Concept Using a Flywhel for Electric Veiicles," DOE/NASA/0078-79/1, NASA CR-159650, Dec, 1979.

8. Raynard, A. E. and Forbes, F. E., "Advanced Electric Propulsion System Concept for Electric Vehicles," DOE/NASA/0081-79/1, NASA CR-159651, Aug. 1979.

9. Swain, J. C., Klausing, T. A., and

Wilcox, J. P., "Design Study of steel V-belt CVT for Electric Vehicles," DOE/NASA/0116-80/1, NASA CR-159845, June 1980 .

10. Walker, R. D. and McCoin, D. K., "Design Study of a Continuously Variable Cone/Roller Traction Transmission for Electric Vehicles," DOE/NASA/0115-80/1, NASA CR-154841, Sept. 1980.
1!. Raynard, A. E., Kraus, J. H., and bell, D. D., "Design Study of Toroidal Traction CVT for Elect:ic Venicles," DOE/NASA/0117-80/1, NASA CR-15y803, Jan. 1980.

12. Kumm, E..L., "Design Study of Flat Belt CVT for Electric Venicies," DOE/NASA/0114-80/1, NASA CR-159822, March 1980.

13. "Belt Drive CVT For ' 82 Model Year," Automotive Eng ineering, Vol. 88, No. 2, Feb. 1980, pp. 136-140.

14. Kumm, Emerson L., "Variable Speed Flat Belt Transmission. U.5. Patent No. 4,024,772.

15. Stubbs, P. W. R., "The Development of a Perbury Traction Transmission for Motor Car Ápplications," ASM paper No. 80-C2/DET-59, presentec at the Century 2 International Power Transmission and Gearing Conference, San Francisco, California, Aug. 18-21, 1980.

Table I. - CVT Concepts for Preliminary Design Study

crT Concept

Steel V-belt

Flat belt

Toroidal traction

Cone-roller traction

\section{Contractor}

Battelle Columius Labs

Columbus, Onio

Kumm Industries, Inc. Tempe, Arizona

Garrete Corporation AiResearch Manufacturing

Co. of California

Torrance, California

Bales-McCoin Tractionmatic El Paso, Texas

\section{Reference}

\section{9}

12

11

10

Table II. - Predicted Efficiency of CVT Concepts at Selected Vehicle Conditions at a Flywhel Speed of $21000 \mathrm{rpm}$

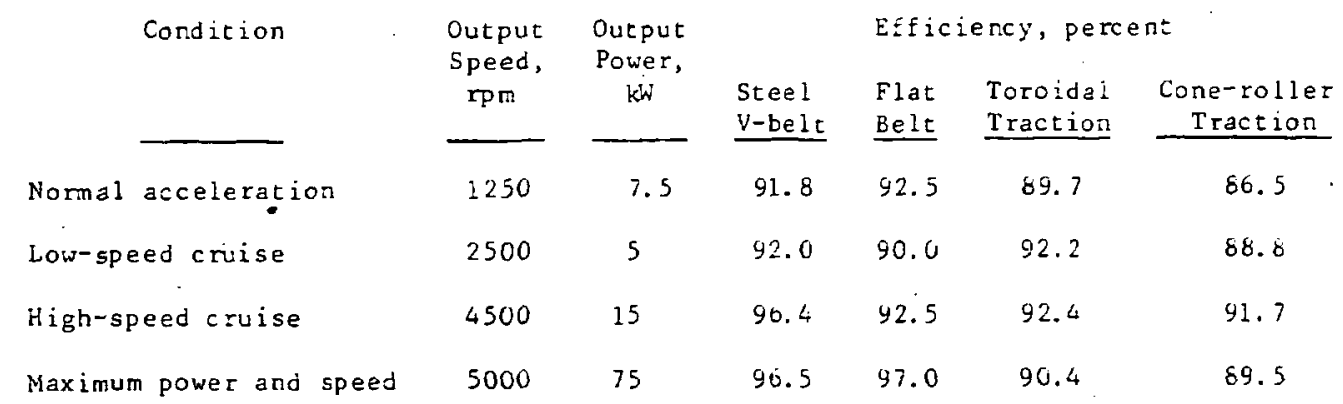

Table III. - Dimensions anc weights of CVT. Concepts

Dimensions, cm(in.)

Concept

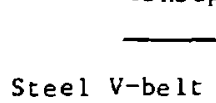

Flat belt

Toroidal craction

Cone-rolier traction

\section{Leng $t h$}

$52: 2(20.6)$

30. $1(11.9)$

$67.3(26.5)$

4l. $3(16.3)$ width

$31.5(13.8)$

$48.4(19.0)$

$23.8(9.4)$

$2 \cdot 7.4(10.8)$
Height

$24.8(9.8)$

$47.6(18.8)$

$36.2(14.3)$

$27.4(10.8)$
Contractor's

estimated

weight,

$\mathrm{kg}(\mathrm{lb})$

$70.3(155)$

$0.1(2.4)$

$44.5(98)$

$62.6(136)$

31. $8(70)$

Parker, Loewenthal, and Fischer 


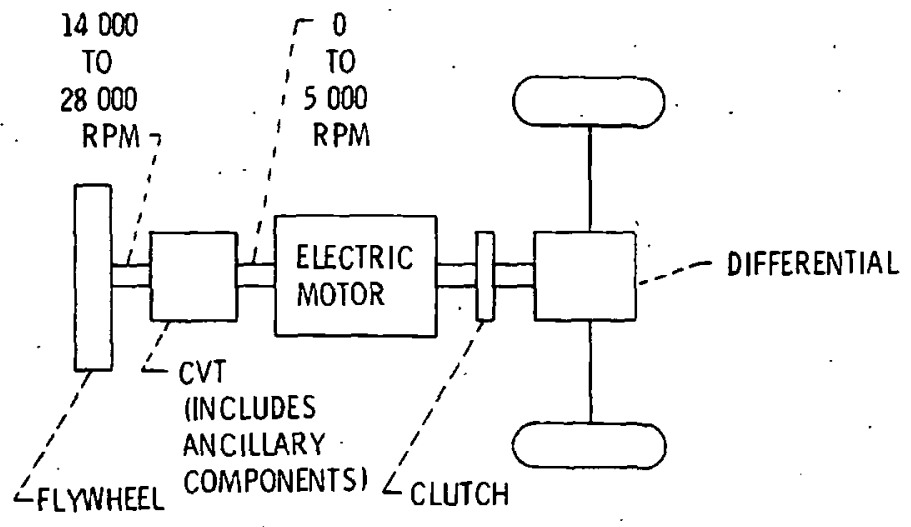

Figure 1. - Arrangement of vehicle drive train for preliminary design studies.

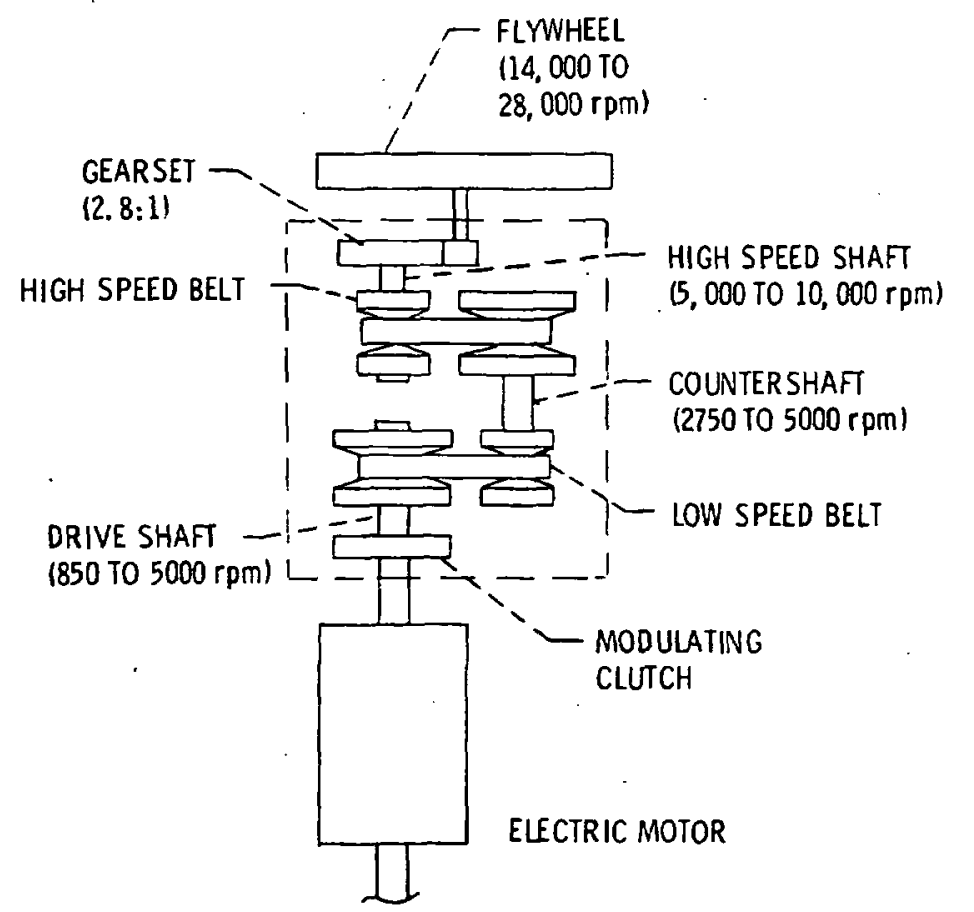

Figure 2. - Steel V-belt CVT schematic arrangement (9). 


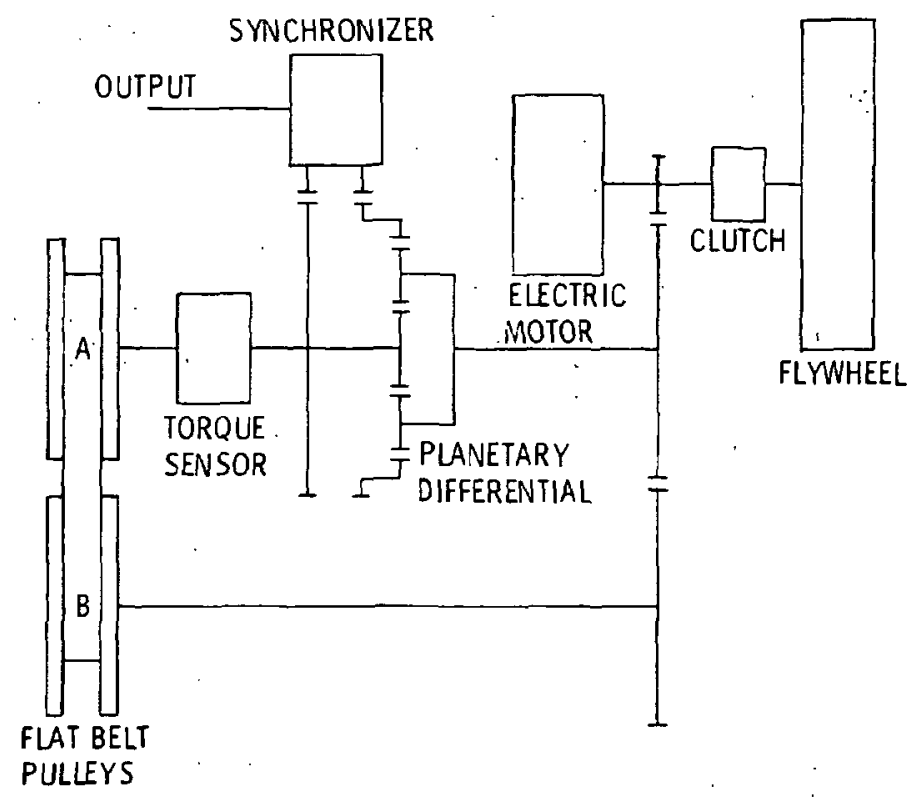

Figure 5. - Schematic representation of flat-belt CVT.

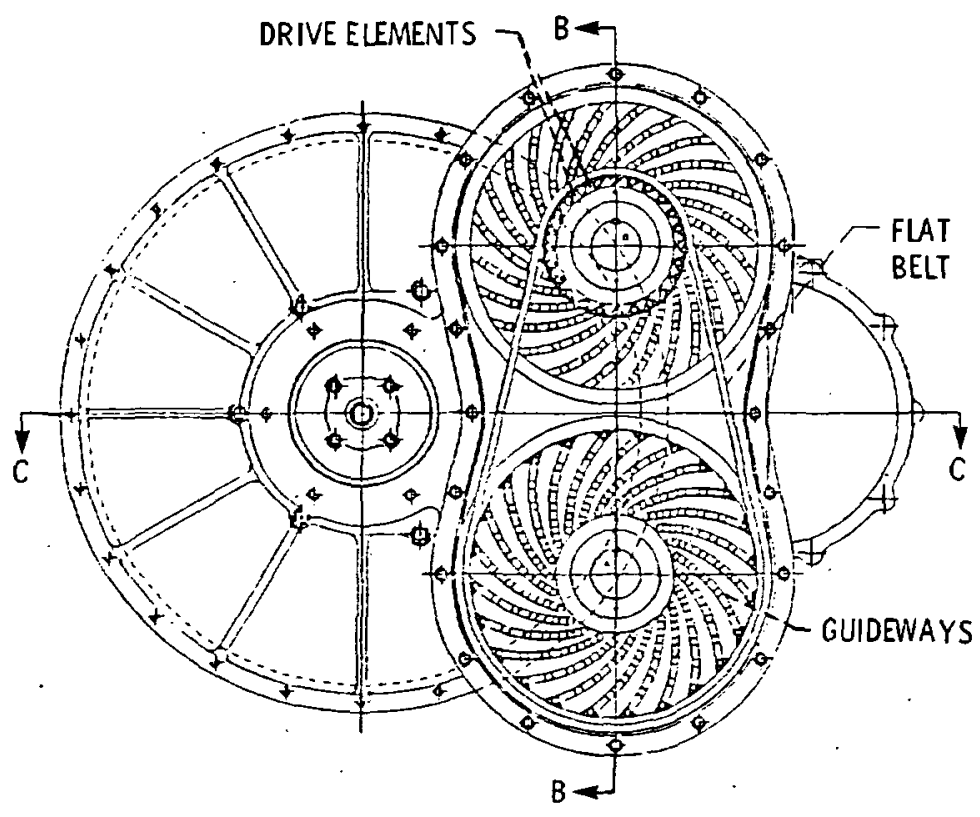

(a) SECTION A-A THROUGH PULIEYS.

Figure 6. - Preliminary layout of flat belt CVT (12). 


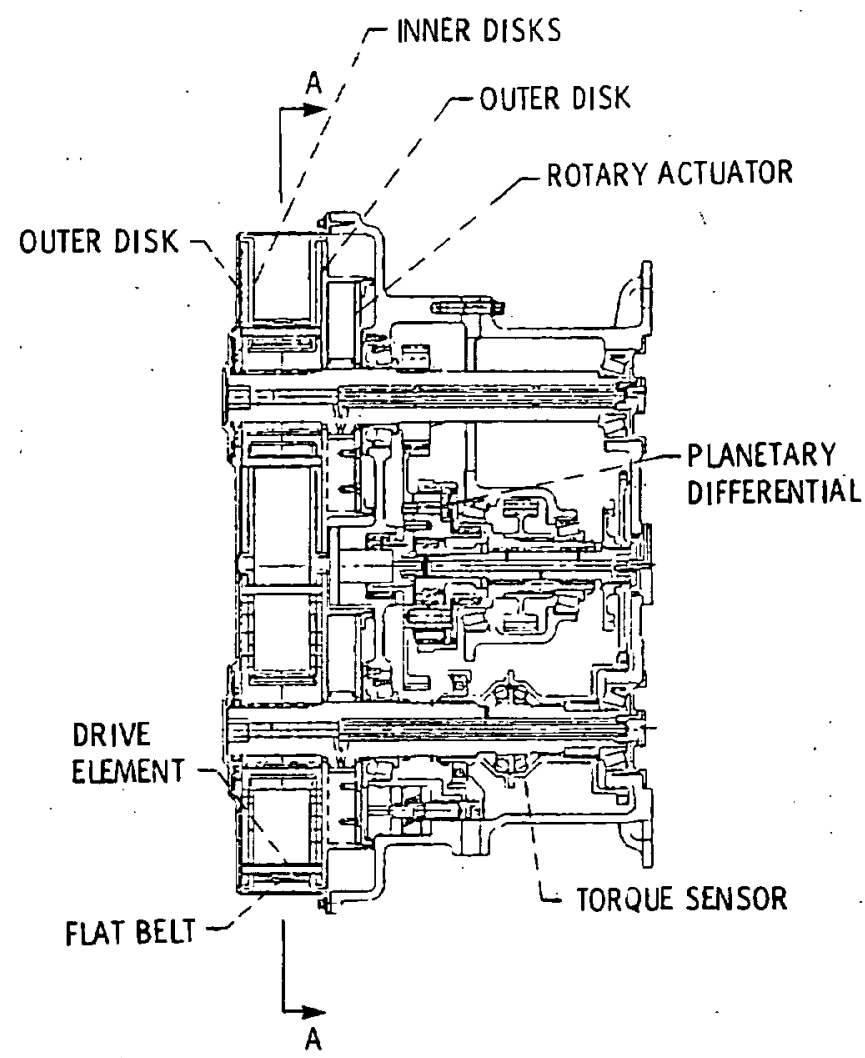

(b) Section B-B through pulleys.

Figure 6. - Continued.

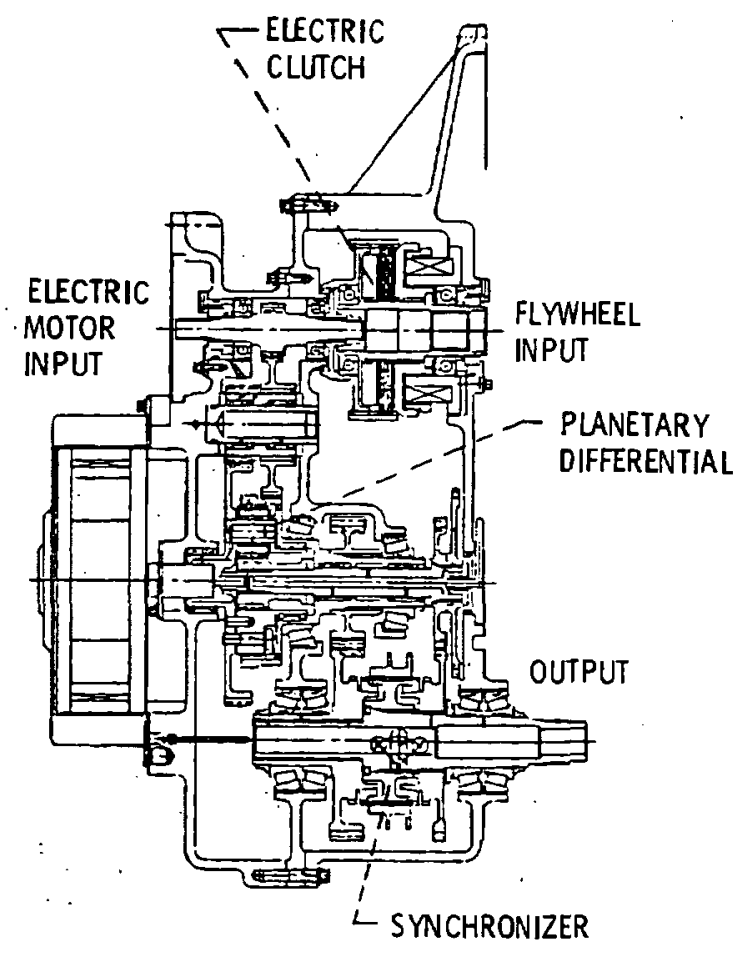

(c) Section C-C through input and output shafts.

Figure 6. - Concluded. 


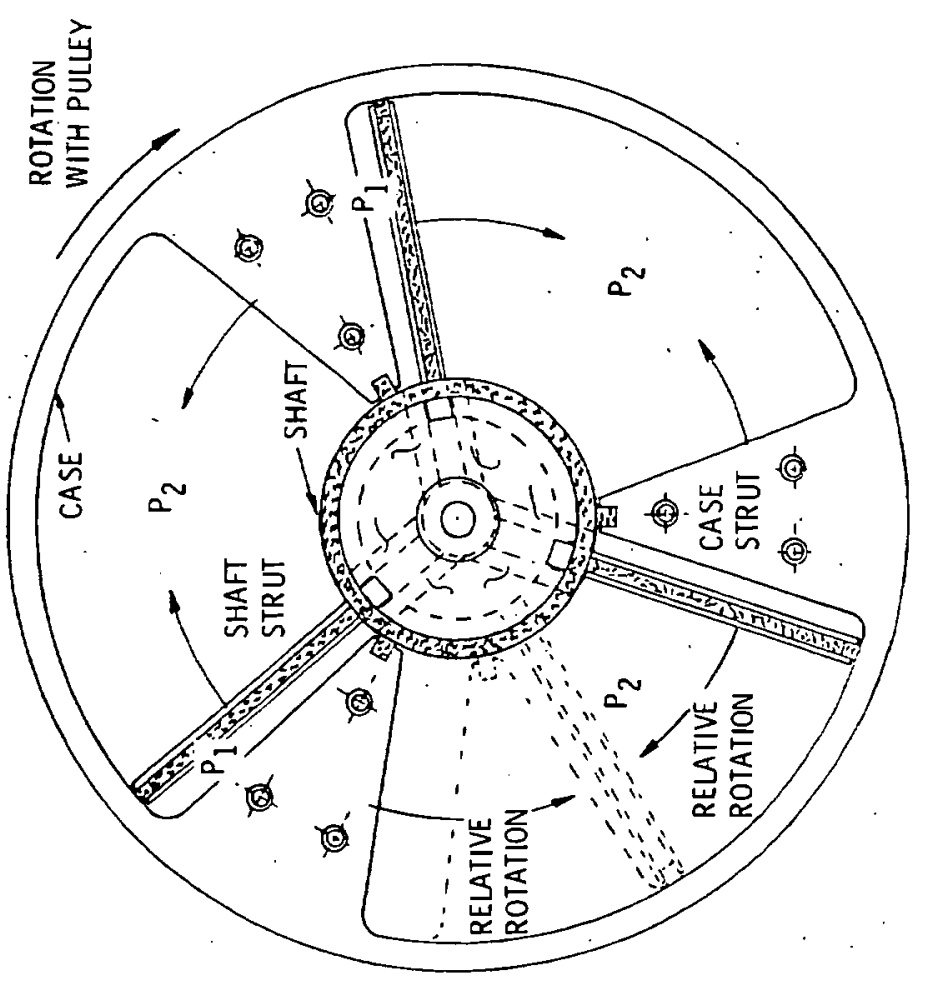

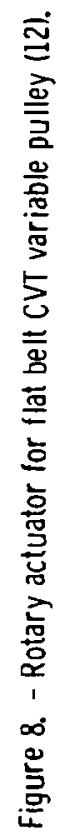

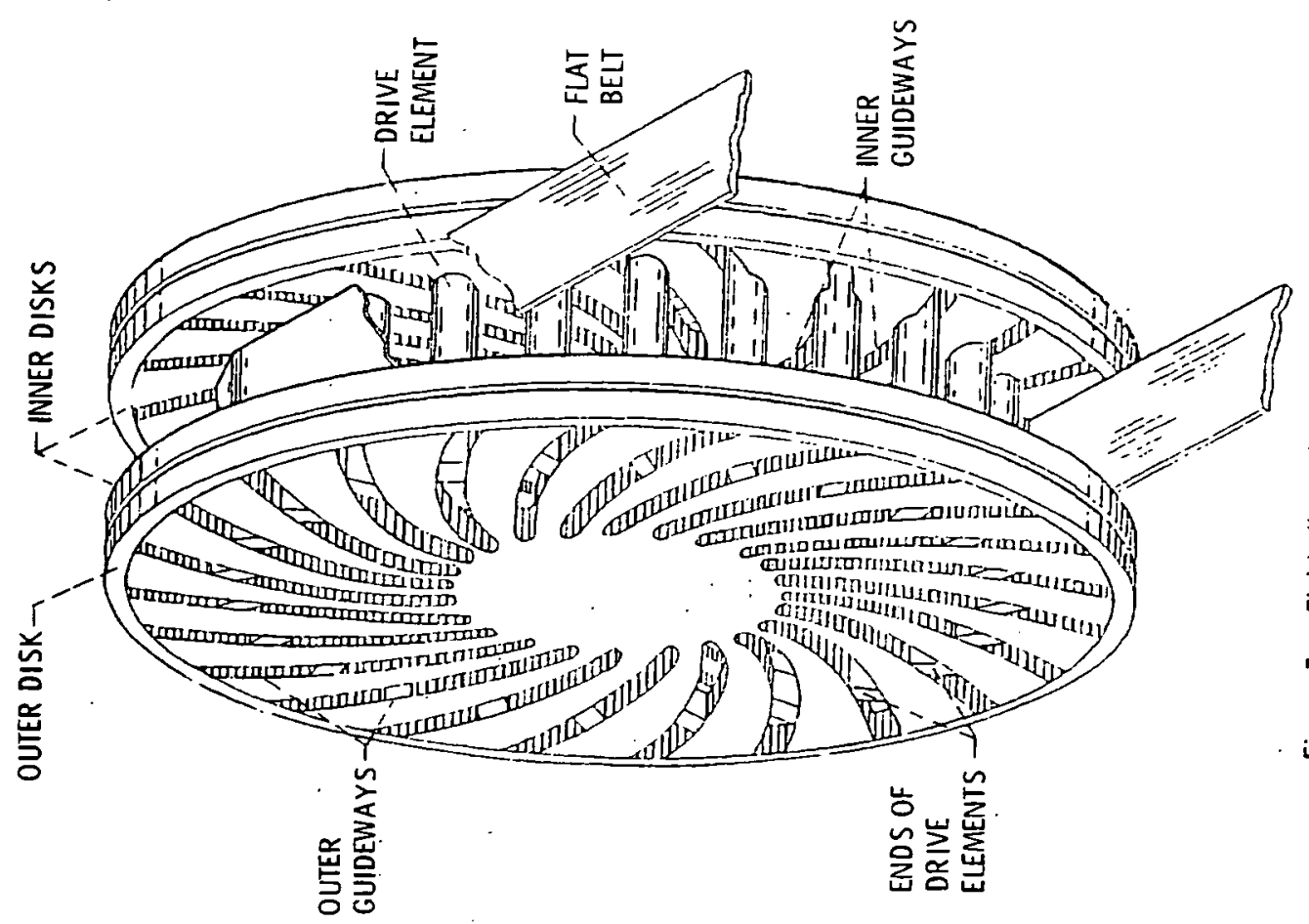

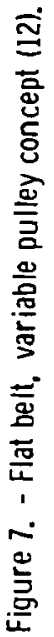




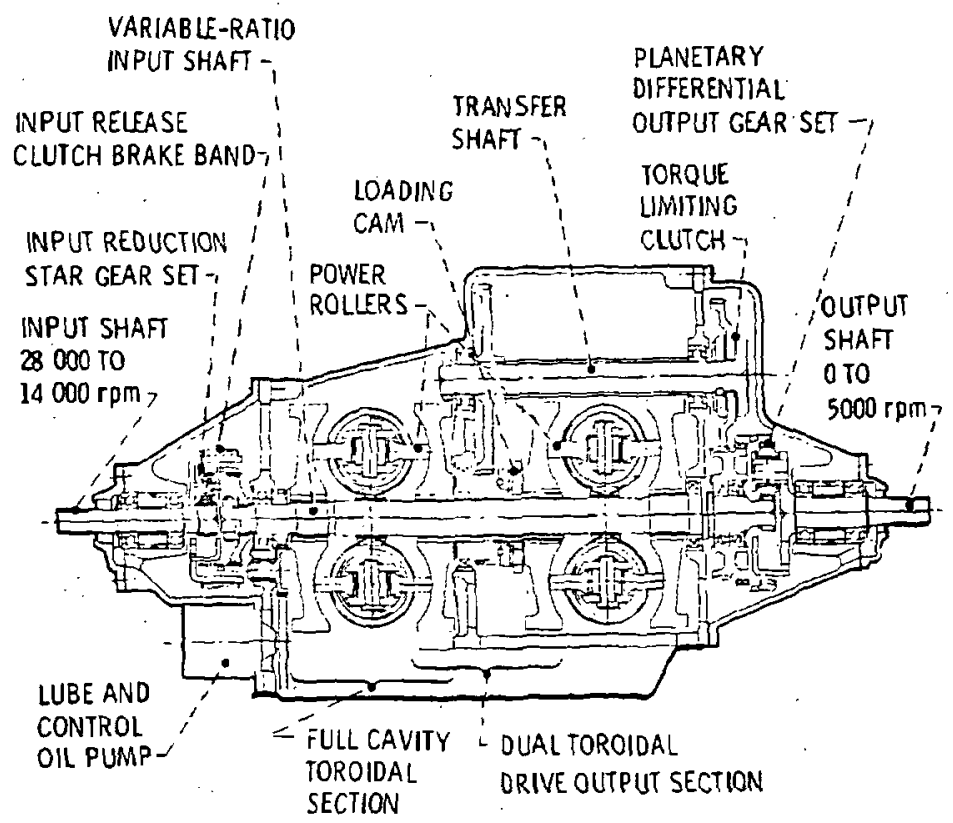

Figure 9. - Preliminary layout of torodial traction CVT (11).

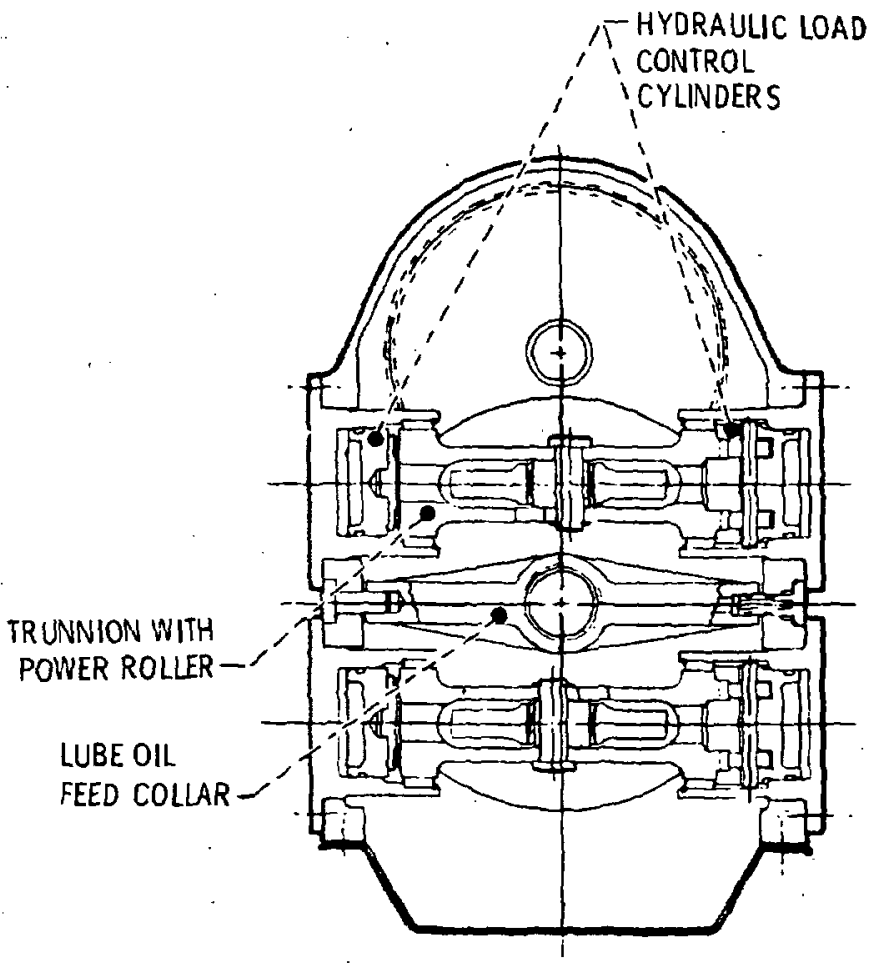

Figure 10. - Hydraulic load control cylinders for drive rollers for toroidal traction CVT (1]). 


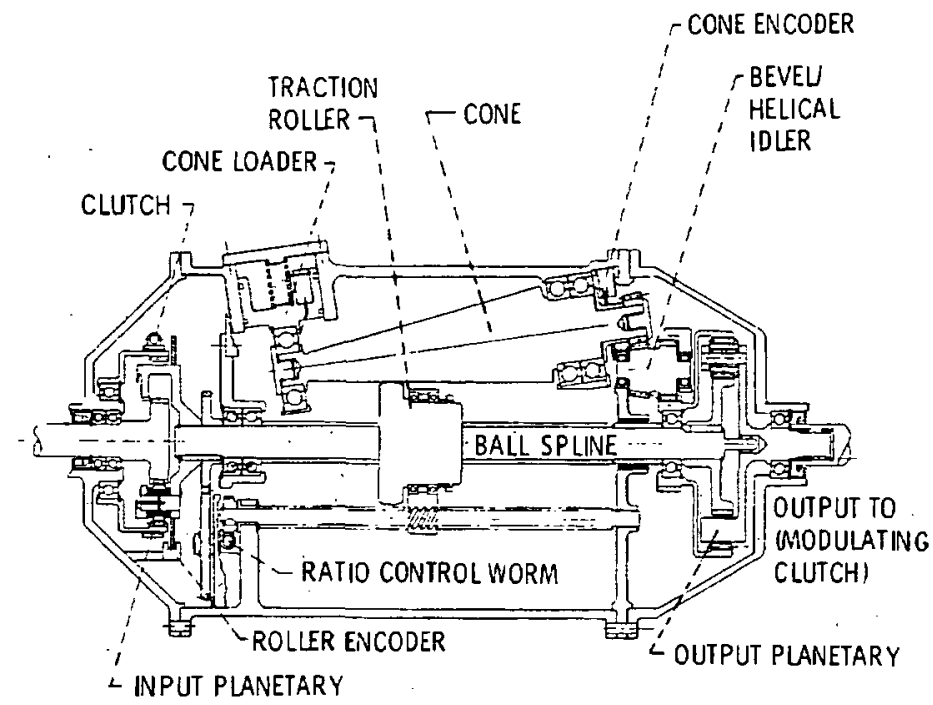

Figure 11. - Preliminary layout of cone-roller traction CVT (10).

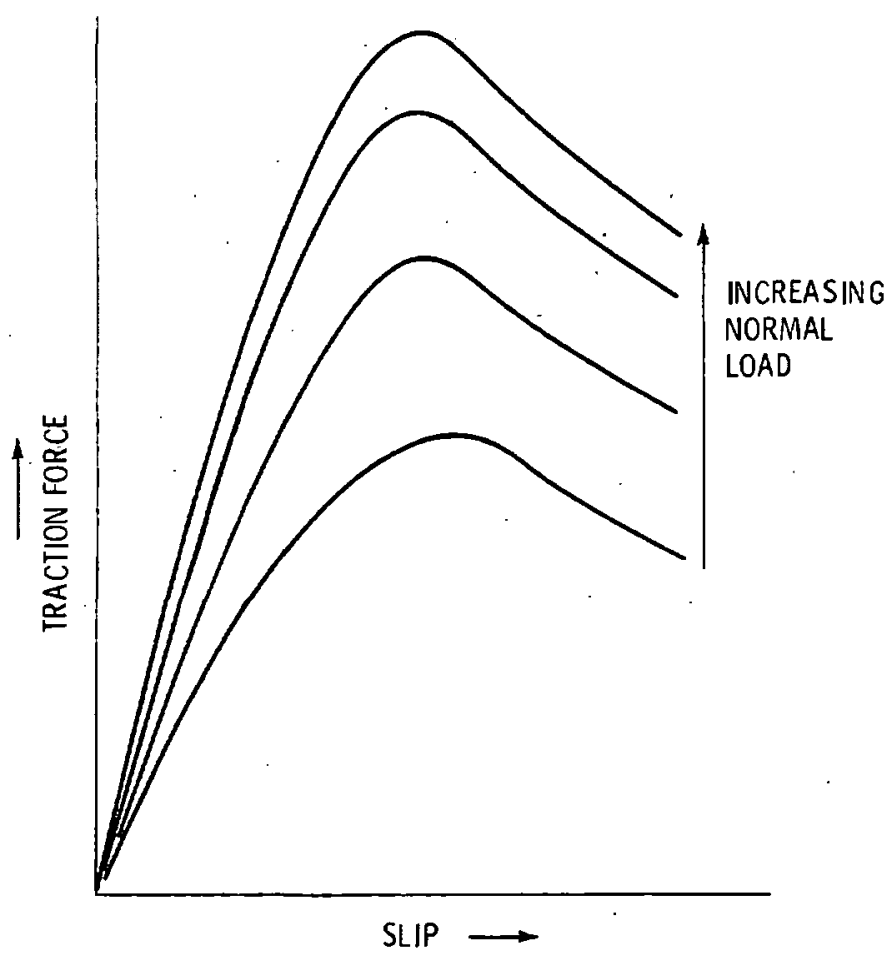

Figure 12. - Traction force as function of slip and nor mal load in a traction contact. 


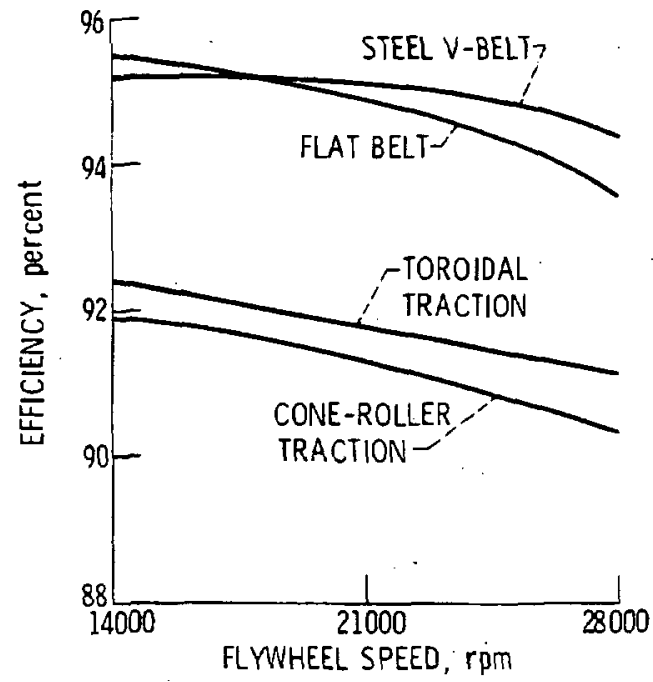

Figure 13. - Predicted efficiencies of the four CVT preliminary designs at an output power of $16 \mathrm{~kW}$ and an output speed of $3000 \mathrm{rpm}$. 